\title{
Uptake of Prevention of Mother to Child HIV Transmission (PMTCT) Option B+ ART Program among Pregnant and Lactating Mothers Attending Ante Natal Care (ANC) Clinic at Jimma University Specialized Hospital, Southwest Ethiopia
}

\author{
Yibeltal Siraneh* \\ Faculty of Public Health, Department of Health Economics, Jimma University, Ethiopia
}

Submission: September 17, 2018; Published: October 26, 2018

*Corresponding author: Yibeltal Siraneh Belete, Department of Health Economics, Management and Policy, Faculty of Public Health, Institute of Health, Jimma University, Ethiopia; Tel: +251917017092; Email: yibeltal_siraneh@yahoo.com; yibeltalsiraneh@gmail.com

\begin{abstract}
Background: Prevention of mother to child transmission (PMTCT) Option B+ART program provide all HIV-positive pregnant or breastfeeding women with a course of anti-retroviral drugs to prevent mother-to-child transmission. A triple-drug anti-retroviral regimen should be taken throughout pregnancy, delivery and breastfeeding - continuing for life, regardless of CD4 count or clinical stage. However, uptake and uptakeof this new approach, among HIV positive pregnant and lactating mothers was not studied in Jimma university specialized hospital; Hence the objective of this study was to assess uptake of PMTCT option B+ ART program among pregnant and lactating mothers attending anti natal care (ANC) clinic at Jimma University specialized hospital.
\end{abstract}

Methods: An institution based cross sectional descriptive study was conducted with the aim of assessing uptake of PMTCT option B+ ART program among HIV positive pregnant \& lactating mothers attending ANC clinic at Jimma University specialized hospital from May 01 to May 30 , 2014. All HIV positive pregnant \& lactating mothers (40) who visited ANC clinic had been interviewed by trained nurse using pretested, closed ended structured questionnaire after respondent consent was taken. Data analysis was done using SPSS 16.0 computer software. Finally data was presented in statement and tables.

Results: Out of 40 pregnant and lactating HIV positive mothers included in the study, almost all of them were found in the age group of 18-35years $(92.5 \%)$ and more than half are literate $25(62.5 \%)$ \& their income per month is less than 900 birr $(72.5 \%)$ as well as $67.5 \%$ of them are house wife who were married (80\%). Twenty eight (87.5\%) of them accepted their HIV positive status due to their history of different exposures and $82.5 \%$ of them were tested during first trimester and almost all of them were using PMTCT option B+ ART service (90\%), and their reason why they accept was for protection of their baby from HIV $(38.71 \%)$ and followed by due to having knowledge after counseling (34.41\%). About two-fifth of mothers were using condom as one contraceptive method. There is association between initial acceptance of HIV positive test result and uptake of PMTCT option B+ ART services.

Conclusion: almost all of HIV positive pregnant \& lactating mothers have accepted their HIV positive status. Two third of them were tested at first trimester, and the uptake of PMTCT option B+ ART service is very high at ANC clinic in Jimma University specialized hospital. So, this new PMTCT option B+ ART program should continue with pre and post-test counseling along with ANC follow up.

Keywords: PMTCT option B+; Uptake; Pregnant and lactating mothers; ANC clinic; JUSH

\section{Introduction}

PMTCT Option B+ is a new program that Provide for all HIV-positive pregnant or breastfeeding women with a course of anti-retroviral drugs to prevent mother-to-child transmission. A triple-drug anti-retroviral regimen should be taken throughout pregnancy, delivery and breastfeeding - continuing for life, regardless of CD4 count or clinical stage [1].

If the mother is breastfeeding, she should also continue to take the triple-drug anti-retroviral regimen until 1 week after breastfeeding has finished. Eligibility is determined at a country level. WHO recommends women with a CD4 count of $\leq 500$ cells/ $\mathrm{mm}^{3}$ (or clinic stage 3 or 4 ) should continue taking anti-retroviral treatment for life. This course of medication should be permanent and taken every day in order to postpone the development of HIV into AIDS. HIV-exposed infants all infants born to HIV positive mothers should receive a course of medication for PMTCT, which is linked to the drug regimen that the mother is taking and the infants feeding method. If Breastfeeding, The infant should receive 
once-daily NVP from birth until age 6 weeks. If Not breastfeeding, the infant should receive once-daily NVP (or twice-daily AZT) from birth until age 4-6 weeks [1]. Option B+ is the way of full integration and simplification at the primary health care level; the good news is that a fully integrated and simplified approach to PMTCT and ART has now begun to be implemented successfully on a large scale. As mentioned earlier, "Option B+" provides a potentially better alternative to Option A or Option B through which all pregnant women living with HIV can initiate ART for life regardless of CD4 count.

Through making a positive HIV test the only condition necessary to initiate ART, Option B+ makes it feasible to implement the most effective PMTCT interventions for mother and child at the smallest and most remote health centers, thereby ensuring that lack of access to CD4 testing does not prohibit women from receiving needed treatment. Additionally, Option B+ also provides a straightforward approach to postnatal follow-up that can be integrated with efforts to help women safely breastfeed their infants. And, by avoiding the "start-stop-start" approach that would be required with option B for many women who might have more than one pregnancy, Option B+ makes it easy to convey clear public health message to all people in the community that ART already started, needs to be adhered to for life. Furthermore, Option B+ offers additional potential health benefits, including reduction in sexual transmission of HIV, improved maternal health, having a programmatic advantage, decreasing MTCT of HIV by $2 \%$, improving of mothers \& child life/survival [2]. WHO released different updated PMTCT programmatic approach like 'Option A', Option B, and Option B+ since 2010.But initiation of ART was depend on CD4 count primarily and the next was start-stop-start approach which is tedious and ineffective one. However, after the latest program "option B+" was recommended in 2012 worldwide, some of developing countries like Malawi, Uganda and Ethiopia have already adopted the latest one, option $\mathrm{B}+$. But its uptakeand refusal status was not studied yet in the study area. Previously, in Ethiopia all pregnant \& lactating mothers who are HIV + were get ART based on their CD4 count but this way was found to be ineffective according to WHO new guideline that made conclusion on CD4 count testing prerequisite for PMTCT as not feasible in Malawi. GoE (MOH) endorsed the strategic shift to "Option B+" in august 2012. But still it may have some implementation gaps that hinder uptake and uptake of mothers towards this new option B+ approach $[3,4]$.

A critical component for how well an intervention will work is how acceptable it is to its recipients/user. In choosing anti-retroviral regimens for PMTCT; the efficacy of a regimen has typically been a much more important criterion than its acceptability, given that it has been justifiably assumed that women will want to use the most effective regimen. However, in cases where two options may have similar efficacy for an individual woman, understanding the relative uptake of the options becomes especially critical from a human rights perspective [5]. Therefore, in comparing Options $\mathrm{A}, \mathrm{B}$, and $\mathrm{B}+$ it is important to hear from women living with HIV themselves regarding which option they would prefer, and also whether they would like to have the opportunity to choose between the two options. Option B and especially Option B+ may have health benefits for women with higher CD4 counts. Nevertheless, the health benefits of Option B+ may not be dramatic compared to option B for women with CD 4 greater than 350, and some fraction of women with CD4 >350 may prefer to stop ART after the cessation of breastfeeding and only re-start again when it is clearly necessary for their own health. With this in mind, countries may want to use qualitative methods such as surveys or focus groups to understand in their own local cultural context women's perceptions, attitudes, and preferences with regards to Options A, B, and B+ [6-8].

According to FMOH-HSDP IV annual performance report for EFY 2004 (2011/2012), The proportion of HIV positive pregnant women who received ARV prophylaxis to reduce the risk of MTCT is at $25.5 \%$ during the fiscal year through only $16.7 \%$ of HIV exposed babies received ARV prophylaxis. This has resulted in a10 fold increase in the number of facilities providing PMTCT services in the last 5 years [9]. In august 2012, the GoE endorsed the strategic shift to PMTCT Option B+ which addresses the four prongs (trained human resource $\&$ scale up of service, PMTCT service quality improvement, and demand creation using health development army, \& monitoring \& evaluation.)For PMTCT \& consists of provision of a single triple drug ART regimen to HIV positive pregnant women without regard to CD4 count \& maintains continuity of care treatment for the mother \& infant within the $\mathrm{MNCH}$, platform from antenatal detection to post-breast feeding testing of the infant. As a new starter also in Ethiopia, uptake of this new program was not studied in JUSH $[10,11]$.

Option B + ART program initiates ART for HIV positive pregnant and lactating mothers at ANC at the time of diagnosis regardless of CD4 level But CD4 count is important to monitor response to treatment \& to detect emergence of treatment failure even though not expected for several years if patient is adherent to treatment because once started it should be continued for life. In line with offering result of HIV test in a confidential manner, counseling should be given as integrated package of services in ANC/labor \& delivery/post-natal services because Prevention, treatment, decision about family or child testing, family planning $\&$ care decision can be made together [12].

Specifically, in JUSH at ANC clinic Option B+ was commenced on August 2013 so it is important assessing HIV positive pregnant and lactating mothers' uptake of this service to dig out the gap since it is new approach. Even though the program was started on August 2013 in JUSH at ANC clinic, specifically the uptake and associated factors of Option B+ was not assessed so far and unknown. Therefore, the aim of this study was to assess uptake of PMTCT Option B+ ART programme during pregnancy and lactating period, assess why the mothers accept or reject the services and assess the awareness level of mothers about option B+.

\section{Methods and Participants}

This study was conducted in Oromia region, Jimma Zone, Jimma town, at Jimma university specialized hospital, obstetrics 
and gynecology department, PMTCT service antenatal care clinic from May 01 to May 30, 2014. It is located $350 \mathrm{~km}$ southwest of Addis Ababa. Currently there are 2 woreda and 17 kebeles and 1 specialized Teaching Hospital, 1 Defense Hospital, 1 police Hospital, 1 Primary Hospital and 3 Health centers found in Jimma town. The study included the specialized teaching hospital. JUSH is a teaching hospital with 65 physicians, 20 pharmacist \& pharmacy technicians,10 radiographers \& radiologists, 218 nurses, 31 midwifes, 21 medical laboratory \& lab technicians and 15 patient registration workers and other like anesthetists, physical therapists. In fact, JUSH was giving ART services as per the protocol at ART clinic for a long period of time but the new PMTCT option B+ program was given at ANC/PMTCT clinic with regular follow up simultaneously with antenatal and post-natal care under obstetrics/gynecology department which is one of specializing area in the hospital. The other departments include pediatrics' and child heath, surgery, internal medicine, ophthalmology, dental medicine, psychiatry, ANT clinic, dermatologic clinic, radiology.

Institution based cross-sectional descriptive study design was used to asses uptake of PMTCT option B+ ART program among all HIV positive pregnant \& lactating mothers attending ANC clinic, department of obs/gynecology, at Jimma University specialized hospital. All HIV positive pregnant \& lactating women were attending JUSH at ANC clinic-starting from HIV positive result finding up to 18 month of postpartum period, option B+ ART follow up of mothers' is taken place at ANC and then linked to regular ART clinic. All HIV positive pregnant and lactating women that were in PMTCT follow up monthly as per their schedule during the study period and all new HIV positive cases who came for ANC visit during that period were included in the study.

A structured interviewer administered pretested data collection format was used to collect data. Data collector translated the English version of the format into the local language to capture data from the study participants. one nurse professional in ANC clinic was trained on how to approach all those old and new HIV positive cases on their monthly follow up day. Always the data collector checked number of patients' chart and presented clients, not to miss those absent appointed mothers of the day before data collection. Then after finishing of each client's interview, the completeness of a single questionnaire was revised in between and finally as a whole by the principal investigator.

Finally, at the end of the month after identifying complete and incomplete questionnaires, the data was filled into computer software step by step with trained personnel and followed strictly along with multiple cross checking; the quality of pre-

Results

\section{Socio-demographic characteristics}

Table 1: Socio-demographic Characteristics of HIV positive pregnant and lactating mothers attending ANC clinic at JUSH, Southwest Ethiopia, 2014.

\begin{tabular}{|c|c|c|}
\hline Characteristics & Number (40) & Percentage \\
\hline Age & & 7.5 \\
\hline$<18 \mathrm{yr}$ & 3 & 92.5 \\
\hline $18-35 \mathrm{yr}$ & 37 & \\
\hline
\end{tabular}


Journal of Complementary Medicine \& Alternative Healthcare

\begin{tabular}{|c|c|c|}
\hline Ethnicity & & \\
\hline Oromo & 15 & 37.5 \\
\hline Amhara & 10 & 25 \\
\hline Tigre & 8 & 20 \\
\hline Other...@@ & 7 & 17.5 \\
\hline \multicolumn{3}{|l|}{ Religion } \\
\hline Muslim & 16 & 40 \\
\hline Orthodox & 13 & 32.5 \\
\hline Protestant & 7 & 17.5 \\
\hline Others (specify).....\#\# & 4 & 10 \\
\hline \multicolumn{3}{|l|}{ No of children } \\
\hline no & 15 & 37.5 \\
\hline One to three & 20 & 50 \\
\hline Above three & 5 & 12.5 \\
\hline \multicolumn{3}{|l|}{ Income per month } \\
\hline$<900$ birr & 29 & 72.5 \\
\hline$>=900 \mathrm{birr}$ & 11 & 27.5 \\
\hline \multicolumn{3}{|l|}{ Occupational status } \\
\hline House wife & 27 & 67.5 \\
\hline Merchant & 9 & 22.5 \\
\hline Other.....** & 4 & 10 \\
\hline \multicolumn{3}{|l|}{ Marital status } \\
\hline Single & 4 & 10 \\
\hline married & 32 & 80 \\
\hline divorced & 3 & 7.5 \\
\hline widowed & 1 & 2.5 \\
\hline
\end{tabular}

$@ @=$ Kaffa, Gurage, Yem, Dawuro, \#\# =Adventist, catholic, ${ }^{* *}=$ farmer, employed,

Among the total of 40 pregnant and lactating HIV positive mothers who visited the hospital during the study period, all of them were included in the study that form the basis of my analysis. Almost all of them $37(92.5 \%)$ were found in the age group of 18$35 y$ rs. Sixteen (40\%) of them were Muslim by religion while more than one third $15(37.5 \%)$ were Oromo by ethnicity. Twenty-five $(62.5 \%)$ of the respondents were literate and more than two third $27(67.5 \%)$ were housewives by occupation. Majority 32 $(80 \%)$ of the women were married whereas half $(50 \%)$ of them had less than or equals to 3 children. Twenty-nine $(72.5 \%)$ of the respondents had monthly income of $<900$ Eth Birr (Table 1).
Out of all pregnant and lactating HIV positive mothers included in the study 28 (87.5 \%) of them accepted their HIV positive status due to having history of different exposures among thirty-three $(82.5 \%)$ of them who were tested at first trimester. Out of 32 mothers who accepted their HIV positive sero status, 28(70\%) of the respondents were perceived as an unprotected sexual intercourse would be a risk factor for their contracting HIV. Forty (26.15\%) of the women were counseled on how to sort \& taking way of option B+ ART program whereas 39(25.49\%) of them were counseled on how to follow up ANC \& get PMTCT services as a main point of posttest counseling at ANC clinic (Table 2).

Table 2: Different variables showing uptake of PMTCT option B+ ART program among pregnant \& lactating women attending ANC clinic at JUSH, Southwest Ethiopia, 2014

\begin{tabular}{|c|c|c|}
\hline Variables & Number/Frequency $* *$ & Percentage \\
\hline \multicolumn{3}{|c|}{ Acceptance status of HIV + Result } \\
\hline $1^{\text {st trimester }}$ accepted & 28 & 87.5 \\
\hline rejected & 5 & 15.63 \\
\hline $2^{\text {nd trimester. }}$ accepted & 3 & 9.38 \\
\hline rejected & 2 & 6.25 \\
\hline $3^{\text {rd trimester. }}$ accepted & 1 & 3.13 \\
\hline rejected & 1 & 3.13 \\
\hline
\end{tabular}


Journal of Complementary Medicine \& Alternative Healthcare

\begin{tabular}{|c|c|c|}
\hline Perceived mode of exposure to HIV historically & & \\
\hline Unprotected sexual intercourse & 28 & 70 \\
\hline blood \& blood product contact & 7 & 17.5 \\
\hline commonly using of sharp materials & 2 & 5 \\
\hline unknown, simply with test result(forgotten) & 3 & 7.5 \\
\hline \multicolumn{3}{|l|}{ Focus of pot test counseling } \\
\hline On how to discuss with husband/sexual partner & 34 & 22.22 \\
\hline On how to live with HIV & 23 & 15.03 \\
\hline On how to sort \& taking way of ART program & 40 & 26.15 \\
\hline On how to protect from secondary exposure & 12 & 7.84 \\
\hline On how to follow up ANC \& get PMTCT services & 39 & 25.49 \\
\hline Others (on social, psychological.......) & 5 & 3.27 \\
\hline \multicolumn{3}{|l|}{ Acceptance of option B + ART service } \\
\hline Accepted & 36 & 90 \\
\hline rejected & 4 & 10 \\
\hline \multicolumn{3}{|l|}{ Reason to accept } \\
\hline wishes to protect baby from HIV & 36 & 38.71 \\
\hline wishes to health of self & 15 & 16.13 \\
\hline b/c of cost free \& accessibility & 10 & 10.75 \\
\hline due to having $\mathrm{k} / \mathrm{dge}$ after counseling & 32 & 34.41 \\
\hline \multicolumn{3}{|l|}{ Reason to reject } \\
\hline Not counseled enough/well. & 2 & 50 \\
\hline not accepted +ve result & 1 & 25 \\
\hline $\mathrm{b} / \mathrm{c}$ of lifelong treatment \& fearing of drug s/ effect & 1 & 25 \\
\hline It is not important to prevent MTCT. & 0 & 0 \\
\hline \multicolumn{3}{|l|}{ Maternal period while starting ART } \\
\hline During first triminister (1-3mon) & 24 & 66.67 \\
\hline During second triminister (4-6mon) & 6 & 16.67 \\
\hline During third triminister (7-9mon) & 4 & 11.11 \\
\hline After delivery (during breast feeding) & 2 & 5.56 \\
\hline
\end{tabular}

${ }^{* *}=$ the sum may not be $40 \mathrm{~b} / \mathrm{c}$ women may answer more than one answer.

Majority 36 (90\%) of mothers have accepted PMTCT option B+ ART program. Their reason for accepting the option includes protection of baby from HIV (38.71\%) and followed by due to having knowledge after counseling (34.41\%). The main reason for those mothers' who rejected option B+ was not being counseled

Table 3: Variables assessed with uptake of PMTCT option B+ ART program among pregnant \& lactating women attending ANC clinic at JUSH, Southwest Ethiopia, 2014.

\begin{tabular}{|c|c|c|}
\hline Variables & Number/frequency ${ }^{* *}$ & percentage \\
\hline Type of contraceptives used & & 39.77 \\
\hline condom & 35 & 36.36 \\
\hline injectable & 32 & 11.36 \\
\hline pills & 10 & 6.82 \\
\hline implants & 6 & 5.68 \\
\hline nothing else used & 5 & \\
\hline Drug side effect observed & & \\
\hline
\end{tabular}

enough/well (50\%). Thirty-six (37.90\%) of mothers were counseled on advantage of the new PMTCT option B+ to accept the treatment so that $24(66.67 \%)$ of them were started the treatment during first trimester and the rest 12 were started on the second \& third trimester (Table 2). 
Journal of Complementary Medicine \& Alternative Healthcare

\begin{tabular}{|c|c|c|}
\hline bowel habit change \& kidney dysfunction & 3 & 8.33 \\
\hline memory problems & 0 & 0 \\
\hline Difficulty of sleeping & 2 & 5.56 \\
\hline skin rash \& headache & 1 & 2.78 \\
\hline no side effect seen & 29 & 80.56 \\
\hline Others.... & 1 & 2.78 \\
\hline \multicolumn{3}{|l|}{ CD4 status/level } \\
\hline$<350$ & 2 & 5 \\
\hline $350-500$ & 3 & 7.5 \\
\hline$>500$ & 13 & 32.5 \\
\hline Not investigated & 22 & 55 \\
\hline \multicolumn{3}{|l|}{ Sexual partner/husband's HIV status } \\
\hline positive & 18 & 45 \\
\hline negative & 10 & 25 \\
\hline not confirmed & 8 & 20 \\
\hline Not investigated & 4 & 10 \\
\hline \multicolumn{3}{|l|}{ Awareness of mothers' about MTCT } \\
\hline during pregnancy & 6 & 15 \\
\hline during delivery & 30 & 75 \\
\hline after delivery & 3 & 7.5 \\
\hline I don't know & 1 & 2.5 \\
\hline \multicolumn{3}{|l|}{ perceived illness after ART started } \\
\hline Cough & 6 & 10.53 \\
\hline diarrhea & 10 & 17.54 \\
\hline Fever & 15 & 26.32 \\
\hline no illness seen & 26 & 45.61 \\
\hline
\end{tabular}

**=the sum may not be $40 \mathrm{~b} / \mathrm{c}$ women may answer more than one answer.

Thirty five $(39.77 \%)$ of mothers' currently using condom as one contraceptive method preferably and followed by injectable $32(36.36 \%)$ whereas 5 (5.68\%) of mothers' who had unprotected sexual intercourse (nothing else used contraceptives).Twenty nine $(80.56 \%)$ of mothers' who were taking triple ART regimen nothing faced any side effect and 22 (55\%) of them were not investigated to $\mathrm{CD} 4$ count that is why option $\mathrm{B}+$ recommended (Table 3 ).

Eighteen (45\%) of mothers' sexual partner/husband sero status is positive, Ten (25\%) of them were negative, eight (20\%) of them were not confirmed and four $(10 \%)$ of them were not investigated due to the reason of not hearing of their wife status and some of them who were negative are due to sero-discordant as well as most of them (75\%) had an awareness about mother to

child transmission mode of HIV is high during delivery. Twenty-six (45.61\%) of women were not faced any type of perceived illness (Table 3).

There is association between initial acceptances of HIV positive test result and uptake of PMTCT option B+ ART service because to start and continue treatment primarily understanding of what diagnosis they have is important so all those accepted $\&$ half of rejected their positive test result were accepted option $\mathrm{B}+$ but all those non-accepted option B+ were not accepted their positive test result from the beginning. Additionally, educational status and acceptance of PMTCT option B+ ART program are associated (Table 4).

Table 4: Association between uptake of PMTCT option B+ ART program and other variables among HIV positive pregnant \& lactating mothers' attending ANC clinic at JUSH, Southwest Ethiopia, 2014.

\begin{tabular}{|c|c|c|c|c|}
\hline Variables & Uptake of PMTCT option B+ ART & Total & Statics/test \\
\hline Initial acceptance of HIV + status & YES & NO & & P $=0.000$ \\
\hline Accepted & 32 & 0 & 32 & Fisher exact test $=17.8$ \\
\hline Rejected & 4 & 4 & 40 & P $<0.05$ \\
\hline Total & 36 & & 25 & Associated \\
\hline Educational status & & $P=0.006$ \\
\hline
\end{tabular}




\section{Journal of Complementary Medicine \& Alternative Healthcare}

\begin{tabular}{|c|c|c|c|c|}
\hline Literate & 25 & 0 & 15 & Fisher exact test $=7.41$ \\
\hline Illiterate & 11 & 4 & 40 & $\mathrm{P}<0.05$ \\
\hline Total & 36 & 4 & & Associated \\
\hline
\end{tabular}

When the assumption for chi-square test failed, I used fisher exact test to see the association.

\section{Discussion}

Thirty-seven (92.5\%) of pregnant and lactating HIV positive mothers were found in the age group of 18-35yrs and more than half (62.5\%) of them are literate. Exactly half (50\%) of respondents had 2 children averagely and majority $(72.5 \%)$ of them had monthly income of $<900$ Eth Birr. This may be due to high number of housewives $(67.5 \%)$ who were married (80\%). Twenty-eight $(87.5 \%)$ of mothers accepted their HIV positive status initially because their acceptance was due to pre and posttest counseling effect in different aspect and their experience of exposure to different risk factors. Most of them (82.5\%) were tested at first trimester so that was because of PMTCT services availability and due to ordering of PICHT (HIV test) when mothers are coming at first visit and they linked to ANC/ PMTCT clinic soon. The focus of posttest counseling was majorly on how to follow up ANC and get PMTCT services but not as much satisfactory because counseling topics were not organized well that is why mothers respond was distributed to all choices and clients were not understand enough.

Almost all (90\%) of mothers were accepted PMTCT option B+ ART program. Their reason for accepting the option includes protection of baby from HIV infection (38.71\%) and followed by due to having knowledge after counseling (34.41\%). so this indicates that they had no awareness about advantage of ART beyond protection to baby rather it decreases viral load and increases the life of patient by delaying disease progress The main reason for those mothers' who rejected option $\mathrm{B}+$ was not being counseled enough/well (50\%). This implies counseling client in different aspect has a great value on acceptance of PMTCT option $\mathrm{B}+$ approach since it is new program. When we compare those who were tested at first trimester and those started ART at first trimester, number of tested was greater than number of client who started treatment $(33>24)$. This gap tell us there was a wide gap of counseling to initiate ART and this gap also may be exaggerated due to non-acceptance of their HIV positive sero status initially.

Thirty-five $(39.77 \%)$ of mothers' currently using condom as one contraceptive method preferably and followed by injectable $32(36.36 \%)$ whereas $5(5.68 \%)$ of mothers' who had unprotected sexual intercourse (nothing else used contraceptives) that may lead them to unwanted pregnancy as well as infection with another type of HIV. Twenty-nine (80.56\%) of mothers' who was taking triple ART regimen nothing faced any side effect and 55\% of them were not investigated to CD4 count that is why option B+ recommended. Twenty (50\%) of mothers' sexual partner/husband sero status was positive and $10 \%$ of them were not investigated due to the reason of not hearing of their wife status and some of them were negative due to sero-discordant. Majority (75\%) of women had awareness about mother to child transmission mode as it is high during delivery.

There is association between initial acceptance of HIV positive test result and uptake of PMTCT option B+ ART program because to start and continue treatment primarily understanding of what diagnosis they had, and its severity is very important. Not only this but also their educational status and acceptance of new option B+ services also had an association because knowing more about science made them to seek treatment and their critical thinking about themselves would help them to go to the solution of the problem.

The new option B+ ART program should continue with enough pre and posttest counseling along with ANC follow up by JUSH, ANC clinic professionals by Promoting and teaching those HIV positive mothers about contraceptives' multiple of benefit for herself (not to acquire other STI) as well as for her baby (if possible not to be pregnant). JUSH, ANC clinic health workers should invest their time to counsel clients not to refuse starting ART earlier at first trimester and should aware all mothers about merit of knowing their HIV sero status before conception rather merely coming for ANC follow up after having pregnancy. This study had many limitations such as small sample size due to the case rarely found, non-sampling technique used which may end up non-generalizability of the finding and strong regression analysis was not done due to the failure of assumption that related with sample size.

\section{Acknowledgment}

First of all, our acknowledgment goes to the almighty GOD that helped me in all the ways. Next, we would like to thank professor kifle $\mathrm{W} /$ mikael and Ato Shimelis Ololo for their constructive comments and suggestion in preparation of this paper and it finalization for publication because of its essentiality and a new approach. Also, we would like to thank Jimma University health Librarians who assisted me by providing necessary references \& computer accesses.

\section{References}

1. http://www.avert.org/who-guidelines-pmtct-breastfeeding htm\#sthash.xSFzu2sW.dpuf

2. FDRE/MOH (2012) Reference manual for PMTCT option B+ update training.

3. FMOH, Annual performance report 2011/2012,

4. FDRE/MOH (2012) Reference manual for PMTCT option B+ update training.

5. Chewe Luo (2012) UNICEF (United Nations Children's Fund), Option B \& B+ acceptability.

6. FMOH, Annual performance report 2011/2012.

7. CDC-Ethiopia office report (2012). 
8. Malawi's Option B+ programme, according to data shown at CROI 2013 (2013).

9. UNICEF (United Nations Children's Fund) (2012) Chewe Luo, option B \& B+ acceptability.

10. FMOH, Annual performance report 2011/2012.

This work is licensed under Creative

Commons Attribution 4.0 License

DOI: 10.19080/JCMAH.2018.08.555738
11. WHO (2012) programmatic update on the use of Anti-retroviral drugs for treating pregnant women and preventing HIV infection in infants: executive summary.

12. WHO (2010) The WHO 2010 infant and young child feeding recommendations 19

\section{Your next submission with Juniper Publishers will reach you the below assets}

- Quality Editorial service

- Swift Peer Review

- Reprints availability

- E-prints Service

- Manuscript Podcast for convenient understanding

- Global attainment for your research

- Manuscript accessibility in different formats

( Pdf, E-pub, Full Text, Audio)

- Unceasing customer service

Track the below URL for one-step submission https://juniperpublishers.com/online-submission.php 